\title{
A facile procedure for tert-butoxycarbonylation of amines promoted by yttria-zirconia based strong Lewis acid catalyst
}

\author{
Rajesh K. Pandey, ${ }^{a}$ Sharda P. Dagade, ${ }^{\mathrm{b}}$ Rajesh K. Upadhyay, ${ }^{\mathrm{a}}$ Mohan K. Dongare, ${ }^{\mathrm{b}}$ and \\ Pradeep Kumar ${ }^{a^{*}}$ \\ ${ }^{a}$ Division of Organic Chemistry : Technology, ${ }^{b}$ Catalysis Division, National Chemical \\ Laboratory, Pune-411008, India \\ Fax: 0091-20-5893614, \\ E-mail: tripathi@dalton.ncl.res.in
}

(received 21 Apr 02; accepted 10 Jun 02; published on the web 18 Jun 02)

\begin{abstract}
A variety of amines react with $\mathrm{Boc}_{2} \mathrm{O}$ in the presence of a catalytic amount of yttria-zirconia based catalyst to afford the corresponding $N$-Boc products in excellent yields.
\end{abstract}

Keywords: Yttria-zirconia based Lewis acid, heterogeneous catalysis, amine, $N$-Boc protected amine, amino acid

\section{Introduction}

The tert-butoxycarbonyl (Boc) is extensively used as an amino protecting group in organic synthesis. ${ }^{1}$ The instability of tert-butyl chloroformate precludes its use for preparing Boc derivatives and so a large number of alternative reagents and methods have been developed of which $\mathrm{Boc}_{2} \mathrm{O}^{2}$ is one of the most commonly reagents used for this purpose. Being inert towards catalytic hydrogenation and extremely resistant towards basic and nucleophilic reagents makes it an ideal orthogonal partner to benzyl esters and carbamates used in peptide synthesis. ${ }^{3}$ In some cases $\mathrm{Boc}_{2} \mathrm{O}$ is also used as an apparent dehydrating agent when it reacts with carboxylic acids, ${ }^{4}$ certain hydroxyl groups ${ }^{5}$ or with primary nitro alkanes. ${ }^{6}$ Although there have been several examples with regards to protection of amines as $N$-Boc group, the use of Lewis acid catalyst to effect the above transformation is rather scarce. One of the methods reported by Porta et al. ${ }^{7}$ used aliphatic amine with diethyl carbonate and catalyzed the transformation with different Lewis acids. However this method could not be extended to the synthesis of $\mathrm{N}$-aryl derivatives.

As part of a research program aimed at developing a new catalyst and its subsequent application for various organic transformations, the yttria-zirconia based Lewis acid ${ }^{8}$ was found to be an extremely efficient catalyst for the Diels-Alder reaction, ${ }^{8}$ transesterification of ß-keto esters ${ }^{9}$ and acylation reactions. ${ }^{10}$ This prompted us to use this catalyst for the synthesis $N$-Boc 
protected amines and herein we report that yttria-zirconia based Lewis acid serves as an excellent catalyst for t-butoxycarbonylation of amines (Scheme 1).

$$
\begin{gathered}
\text { R-NH } 2 \underset{\mathrm{Boc}_{2} \mathrm{O}}{\frac{\text { Ytria-zirconia catalyst, MeCN, rt }}{\longrightarrow} \mathrm{R}-\mathrm{NH}-\mathrm{Boc}} \\
\mathrm{R}=\text { alkyl, aryl, benzyl, heterocyclic, amino acid }
\end{gathered}
$$

\section{Scheme 1}

\section{Results and Discussion}

When a variety of amines were treated with $\mathrm{Boc}_{2} \mathrm{O}$ in the presence of catalytic amount of the new yttria-zirconia based catalyst, the corresponding $N$-Boc protected amines were obtained in excellent yields. The substrates examined in our studies and the results obtained are summarized in Table 1. Thus, the present procedure to introduce the tert-butoxycarbonyl (Boc) protecting group is quite general as a wide range of structurally varied amines such as open chain, cyclic, aromatic, heteroaromatic, amino acid underwent reaction smoothly with $\mathrm{Boc}_{2} \mathrm{O}$. While the conversion of aniline to the corresponding Boc-derivative appears to be sluggish at room temperature with or without catalyst (Table 1, entries 5,6), the reaction could be completed within a short span of time (3h) under reflux conditions (Table 1, entry7). With the introduction of an electron-withdrawing substituent on the aromatic ring (i.e. carbonyl or nitro group), the amine was rendered less nucleophilic and the reactions were sluggish. However, excellent yields of product were obtained (Table 1 , entries 8,9). It is noteworthy that the reaction is chemo selective in the case of 2-aminophenol as the amine, being more nucleophilic than alcohol, underwent reaction faster giving the corresponding $N$-Boc product in high yield (Table 1 , entry 13). Similar is the case with 2-aminoethanol where the $N$ - Boc protected product was obtained in reasonably good yield (Table 1 , entry 18). Another notable feature of the reaction is that even a secondary amine reacted smoothly to afford the product in high yield (Table 1, entries 2,15).

Mention must be made here that the amino group in amino acids could be protected easily, demonstrating the practical utility of this protocol particularly in peptide synthesis. Thus $L$ phenylalanine acid/ester was smoothly converted to the corresponding carbamate in excellent yield (Table 1, entries 16,17). Under the reaction conditions employed, the ester remains unaffected and there is no racemization of the chiral substrate encompassing amino acid. So this protocol could be useful and further be extended to the peptidomimetic synthesis.

It should be pointed out here that although the reactions of amines with $\mathrm{Boc}_{2} \mathrm{O}$ in the presence of DMAP are well studied, the formation of side products in large amounts has recently been observed by Hassner et al. during the course of their revisit into this reaction. ${ }^{11}$ However, the same reaction in the presence of yttria- zirconia based Lewis acid catalyst under the reaction 
condition employed did not lead to any side products. In this connection, our methodology for $N$ Boc protection is noteworthy.

Table 1. Conversion of amines to $N$-Boc derivatives catalyzed by yttria-zirconia based Lewis acid

\begin{tabular}{|c|c|c|c|c|}
\hline Entry & Amine & Reaction time (h) & Product $^{\mathrm{a}}$ & Yield $^{\mathrm{b}} \%$ \\
\hline 1 & & 3 & JHBoc & 90 \\
\hline 2 & & 4 & & 60 \\
\hline 3 & & 5 & & 90 \\
\hline 4 & & 10 & & 95 \\
\hline 5 & & 14 & & 90 \\
\hline 6 & & 48 & & $60^{c}$ \\
\hline 7 & & 3 & & $96^{\mathrm{d}}$ \\
\hline 8 & & 8 & & $91^{\mathrm{d}}$ \\
\hline 9 & & 8 & & $85^{\mathrm{d}}$ \\
\hline 10 & & 8 & & 90 \\
\hline 11 & & 8 & & 90 \\
\hline 12 & & 6 & & 94 \\
\hline 13 & & 6 & & 89 \\
\hline 14 & & 8 & & 90 \\
\hline 15 & & 4 & & 85 \\
\hline 16 & & 6 & & 87 \\
\hline 17 & & 5 & & 90 \\
\hline 18 & 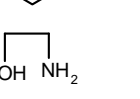 & 3 & & 80 \\
\hline
\end{tabular}

\footnotetext{
${ }^{\mathrm{a}}$ Product was characterized by spectroscopic data. ${ }^{\mathrm{b}}$ yields refer to isolated pure products. ${ }^{\mathrm{c}}$ reaction carried out at room temparature without catalyst. ${ }^{\mathrm{d}}$ reaction performed under reflux condition.
}

A time dependent study of reaction of aniline with $\mathrm{Boc}_{2} \mathrm{O}$ in the absence and in the presence of varying concentrations of yttria-zirconia catalyst indicated that even a small amount of 
catalyst (10 wt \%) can catalyze and accelerate the reaction. However, high yields of $N$-Boc derivatives and high efficiency of the reaction are found only using catalyst (20 wt \%). In the absence of the catalyst, the limited carbamation occurred very slowly even when the reaction was continued for 48h (Table 1, entry 6) The plausible mechanism can be visualized as the activation of the carbonyl group of Boc anhydride by the Lewis acid sites of the catalyst followed by nucleophilic attack of amine to the Boc anhydride. This facilitates the extrusion of $t$ butanol and carbon dioxide as leaving entities eventually leading to the formation of $N$-Boc protected amines.

The heterogeneous catalytic method described here is profitable as it provides high yields of the product and does not involve the use of stoichiometric amount of reagent such as base for $N$ Boc protection. In addition, the reaction conditions are particularly mild and the work-up procedure is exceedingly simple and reduced to a mere filtration. Another significant advantage of the present method lies in the simplicity involved in the preparation of the catalyst. The recovered catalyst can be reactivated for reuse by heating it at $500{ }^{0} \mathrm{C}$ in the presence of air. The same catalyst was recycled for all the reaction without loss of activity and selectivity.

\section{Conclusions}

In summary, a facile heterogeneous catalytic method for the protection of amine as $N$-Boc group employing a novel yttria-zirconia based Lewis acid catalyst has been developed. To the best of our knowledge, this is the first report of use of Lewis acid catalyst for amino group protection using Boc anhydride. Furthermore, the present protocol offers mild reaction conditions, selectivity and short reaction times. The noteworthy feature of this methodology is that chiral substrates are resistant to racemization and labile functionalities, such as esters, are compatible with the reaction condition. In addition, the heterogeneous catalytic method is advantageous in respect of easy separation, higher and consistent yields and recyclability of the catalyst. Thus the present catalytic method should offer a general synthetic method for various carbamates offering a wide variety of application. Further work to extend this protocol as a protecting group for hydroxyl or thiol functionalities is in progress.

\section{Experimental Section}

General Procedures. Solvents were purified and dried by standard procedures before use according to reported procedure; petroleum ether of boiling range $60-80{ }^{\circ} \mathrm{C}$ was used. The amines and $\mathrm{Boc}_{2} \mathrm{O}$ were obtained from commercial sources and were purified by distillation/recrystallization before the experiment. Infrared spectra were recorded with ATI MATT-SON RS-1 FT-IR spectrometer. Proton NMR spectra were recorded on Bruker AC-200 machine in $\mathrm{CDCl}_{3}$ with TMS as internal standard. Mass spectra were obtained with Finningen 
MAT mass spectrometer. The diffractogram of X-ray powder diffraction pattern was recorded on a Rigaku diffractometer model D/Max. IIIVC with $\mathrm{N}$-filtered $\mathrm{Cu}-\mathrm{K} \alpha$ radiation. FTIR spectrum of pyridine adsorbed on the yttrium-based catalyst was recorded on a Nicolet 60 SXB FTIR spectrometer. TPD profile (ammonia) of the yttrium-based catalyst was recorded on a Sorbstar apparatus. Determination of specific surface area was carried out by BET (Brunner-EmmettTeller) $\mathrm{N}_{2}$ adsorption using an Omnisorp 100CX apparatus.

General experimental procedure for the reaction of amines with $\mathrm{Boc}_{2} \mathrm{O}$ : Formation of $\mathrm{N}$-Boc products

In a typical experimental procedure, $\mathrm{Boc}_{2} \mathrm{O}(2 \mathrm{mmol})$ in dry acetonitrile $(1.5 \mathrm{~mL})$ was added dropwise to a solution of amine $(2 \mathrm{mmol})$ in dry acetonitrile $(2.5 \mathrm{~mL})$ containing catalyst $(20 \%$ by weight) with constant stirring and the mixture was stirred at room temperature for the indicated length of time (Table 1). The reaction was monitored by TLC. After completion of reaction, the catalyst was filtered and washed thoroughly with ether $(50 \mathrm{ml})$. The filtrate was washed with $10 \%$ sodium bicarbonate solution, then water, brine and dried over anhydrous sodium sulfate. Evaporation of solvent gave the crude product, which was purified by neutral alumina column using petroleum ether: ethyl acetate (97:03) as eluent to give the pure product.

\section{Synthesis of the catalyst}

The catalyst was prepared by mixing aqueous solutions of yttrium nitrate and zirconyl nitrate in the mole ratio 16:84, to which aqueous ammonia (28\%) was added under vigorous stirring until a $\mathrm{pH}$ of 8.5 was achieved and precipitate was formed. Washing with deionized water, drying at $110^{\circ} \mathrm{C}$ for 24 hours, treating with sulfuric acid (4M), drying at $120^{\circ} \mathrm{C}$ and subsequent programmed calcination at $500^{\circ} \mathrm{C}$ for 3 hours at a heating rate of $2^{\circ} \mathrm{C} \mathrm{min}{ }^{-1}$ resulted in a highly acidic material. The chemical composition of the final catalyst (determined by XRF technique) was found to be $82.6 \mathrm{~mol} \% \mathrm{Zr}, 15.6 \mathrm{~mole} \% \mathrm{Y}$ and $1.8 \mathrm{~mol} \% \mathrm{~S}$. The physicochemical characterization of the catalyst was carried out by titration, temperature programmed desorption (TPD), scanning electron microscopy (SEM) and $\mathrm{N}_{2}$ adsorption techniques.

\section{Acknowledgements}

RKP thanks CSIR, New Delhi for award of Senior Research Fellowship. We are grateful to Dr. M. K Gurjar, Head, Organic Chemistry: Technology Division for his constant encouragement and support. This is NCL communication No. 6624. 


\section{References}

1. Green, T. W.; Wuts, P. G. M. Protective Groups in Organic Synthesis, $2^{\text {nd }}$ Edn.; Wiley: New York 1999; pp503-550 and references therein. Caroino, L. A. Acc. Chem. Res. 1973, 6, 191. Xiuo, X. Yi.; Ngu, K. ; Choa, C.; Patel, D. V. J. Org. Chem. 1997, 62, 6968.

2. Pope, B. M.; Yamamoto, X.; Tarbell, D. S. Org. Synth. Coll. 1988, vi , 418.

3. (a) Mckay, F. C.; Albertson, N. F. J Am. Chem. Soc. 1957, 79, 4686. (b) Anderson, G. W.; McGregor, A. C. J. Am. Chem. Soc. 1957, 79, 6180. (c) Carpino, L. A. J. Am. Chem. Soc. 1957, 79, 98.

4. (a) Pozdnev, V. F. Tetrahedron Lett. 1995, 36, 7115. (b) Pozdnev, V. F. Int. J. Peptide Protien Res. 1994, 44, 36. (c) Takeda, K.; Akiyama, A.; Nakamura, H.; Takizawa, S.; Mizuno, Y.; Takayanagi, H.; Harigaya, Y. Synthesis 1994, 1063.

5. Mattern, R. -H Tetrahedron Lett. 1996, 37, 291.

6. Basel, Y.; Hassner, A. Synthesis 1997, 903

7. Porta, F. Cenini, S. Gazz. Chim. Ital. 1985, 115, 275.

8. Keshavraja, A.; Hegde, V. R.; Pandey, B.; Ramaswamy, A. V.; Kumar, P.; Ravindranathan, T. Angew. Chem., Int. Ed. 1995, 34, 2143; US Patent 5, 932, 752, 1999.

9. Kumar, P.; Pandey, R. K. Synlett 2000, 251.

10. (a) Kumar, P.; Pandey, R. K.; Bodas, M. S.; Dongare, M. K. Synlett 2001, 206. (b) Kumar, P.; Pandey, R. K.; Bodas, M. S.; Dagade, S. P.; Dongare, M. K.; Ramaswamy, A. V. J. Mol. Catal. A: Chemical 2002, 187, 207.

11. Basel, Y.; Hassner, A. J. Org. Chem. 2000, 65, 6368. 